\title{
Francisco Delich In memorian A propósito de las ciencias sociales en Córdoba
}

Marta Philp ${ }^{1}$

Toda escritura tiene un contexto de producción que la permite y la prohíbe. En este caso, un hecho tan fortuito como la muerte de una persona, Francisco Delich, es el acontecimiento que motiva estas páginas e inevitablemente me conduce a pensar en las ciencias sociales en Córdoba, una ciudad y una universidad que lo contó como un protagonista ineludible, como un actor clave en la promoción de las disciplinas centradas en analizar lo humano.

Escribo estas líneas en un contexto donde las ciencias sociales cuentan desde hace poco tiempo con su propia Facultad, conformada por tres carreras de grado: Trabajo Social, Sociología y Ciencia Política y dos Institutos de investigación; uno de ellos, el Centro de Estudios Avanzados, fundado por iniciativa de Francisco Delich a comienzos de los años noventa del siglo pasado. Pero esta revisión del lugar de las ciencias sociales en Córdoba cobra sentido si la hacemos desde una mirada de larga duración, que atraviesa todo el siglo XX, cuando el conocimiento de lo humano fue disputado por distintos campos del saber, por lo tanto, espacios de poder, surcados por la dicotomía sagrado-laico, que tuvo en la Universidad Nacional de Córdoba un escenario privilegiado desde los tiempos que antecedieron a la Reforma Universitaria de 1918.

Esta dicotomía se expresó en distintos momentos: en el Homenaje de despedida a la Córdoba docta y santa, escrito en 1927 por el fisiólogo alemán Georg Nicolai; en las historias escritas por el sacerdote-historiador monseñor Pablo Cabrera y por Enrique Martínez Paz, reformista y promotor de instituciones como el Instituto de Estudios Americanistas en la

\footnotetext{
${ }^{1}$ Directora de la Escuela de Historia de la Universidad Nacional de Córdoba (UNC).
} 
Facultad de Filosofía y Humanidades, punto de inicio de la profesionalización de la historia en Córdoba; en las formas de concebir la universidad durante los gobiernos que asumieron después de cada uno de los golpes de estado que dieron lugar a dictaduras cívico-militares; en las distinciones honoris causa otorgadas a Juan Domingo Perón y al arzobispo de Córdoba Raúl Francisco Primatesta en 1948 y 1973 respectivamente.

A lo largo de todo el siglo XX, y hasta el presente, la manera de concebir la sociedad como un orden natural, fundado en el integrismo católico, que necesita ser resguardado frente a los avances de la modernidad, mantuvo su hegemonía. Su fortaleza constituyó un obstáculo para el desarrollo de las ciencias sociales, basadas en una mirada despojada de fundamentalismos religiosos. Su tardía institucionalización encuentra en este factor ideológico, que sustentó y sustenta las estructuras de poder de la sociedad mediterránea, una de las variables explicativas omnipresentes. $\mathrm{Y}$ es en este contexto de larga duración donde elijo situar la figura de Francisco Delich, quien desde sus iniciativas y concreciones, formando parte de las estructuras de gobierno de la Universidad Nacional de Córdoba y a partir de un conocimiento profundo de esta dicotomía, abrió un espacio para pensar lo humano horadando esta manera hegemónica de explicar el orden social.

Sus escritos en las revistas Jerónimo y Pasado y Presente en los años sesenta y los tempranos setenta; sus análisis del Cordobazo, realizados al calor de los acontecimientos; su historización de la sociología argentina -donde tomaba posición respecto a los enfoques existentes- revisitada en los últimos años, constituyen huellas de sus intervenciones que pusieron al descubierto las condiciones materiales que sustentaban el orden natural, presentado por quienes lo defendían como omnipresente, existente desde el comienzo de los tiempos, excluyente de otras maneras de concebir el desarrollo de las sociedades. Los textos de Francisco Delich, sus logros institucionales, su apertura a nuevas miradas y generaciones tributaron homenajes a este papel fundante de las ciencias sociales: contribuir a explicar el funcionamiento del mundo real para que estas explicaciones constituyan recursos claves en la elección de los caminos a seguir. En estas líneas elegimos recordar al intelectual, al gestor de instituciones, que desde distintos escenarios aportó a la desnaturalización de un orden que se presentaba instaurado de una vez y para siempre. Vayan las mismas como un necesario homenaje y una invitación a reconstruir una historia social de las intervenciones intelectuales en nuestra ciudad mediterránea. 